Title: The molecular proceedings of biological hydrogen turnover

Author(s): Haumann, M.; Stripp, S. T.

Document type: Postprint

Terms of Use: $\quad$ Copyright applies. A non-exclusive, non-transferable and limited right to use is granted. This document is intended solely for personal, non-commercial use.

Citation:

Haumann, M., \& Stripp, S. T. (2018). The Molecular Proceedings of Biological Hydrogen Turnover. Accounts of Chemical Research, 51(8), 1755-1763.

https://doi.org/10.1021/acs.accounts.8b00109

This document is the Accepted Manuscript version of a Published Work that appeared in final form in Accounts of Chemical Research, copyright (0 American Chemical Society after peer review and technical editing by the publisher. To access the final edited and published work see $h$ ttp://dx.doi.org/10.1021/acs.accounts.8b00109. 


\section{The Molecular Proceedings of Biological Hydrogen Turnover}

Michael Haumann ${ }^{\dagger *}$ and Sven T. Stripp ${ }^{\dagger *}$

$\dagger$ Department of Physics, Biophysics of Metalloenzymes, Freie Universität Berlin, 14195 Berlin, Germany

† Department of Physics, Experimental Molecular Biophysics, Freie Universität Berlin, 14195

Berlin, Germany

* E-mail: michael.haumann@fu-berlin.de and sven.stripp@fu-berlin.de 


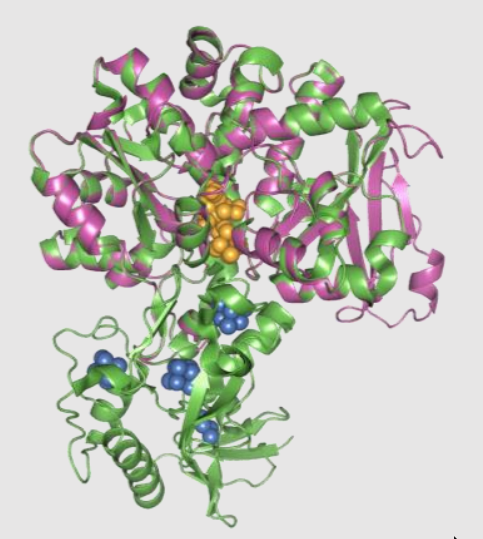

$[\mathrm{FeFe}]-$
hydrogenase

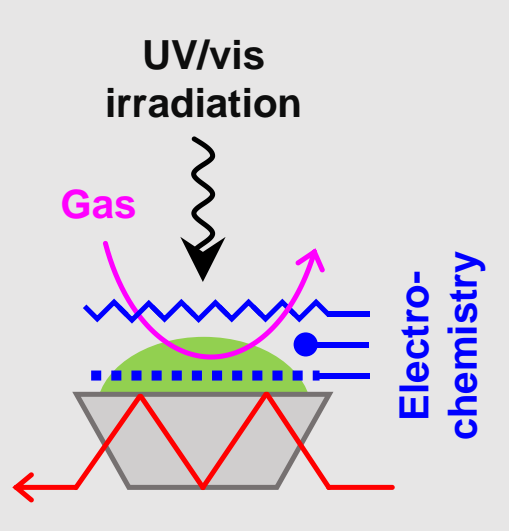

ATR FTIR Spectroscopy

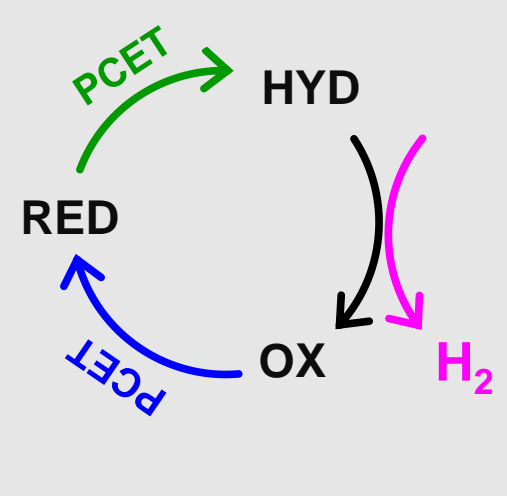

DFT $\begin{gathered}\text { Catalytic } \\ \text { Mechanism }\end{gathered}$

\section{Conspectus}

Over the past two decades, the bioinorganic chemistry of hydrogenases has attracted much interest from basic and applied research. Hydrogenases are highly efficient metalloenzymes that catalyze the reversible reduction of protons to molecular hydrogen $\left(\mathrm{H}_{2}\right)$ in all domains of life. Their ironand nickel-based cofactors represent promising blueprints for the design of biomimetic, synthetic catalysts. In this review, we address the molecular proceedings of hydrogen turnover with [FeFe]hydrogenases.

The active site cofactor of [FeFe]-hydrogenases ("H-cluster") comprises a unique diiron complex linked to a $[4 \mathrm{Fe}-4 \mathrm{~S}]$ cluster via a single cysteine. Since it was discovered that a synthetic analogue of the diiron site can be incorporated into apo-protein in vitro to yield fully active enzyme, significant progress has been made towards a comprehensive understanding of hydrogenase catalysis. The diiron site carries three to four carbon monoxide $(\mathrm{CO})$ and two cyanide $\left(\mathrm{CN}^{-}\right)$ligands that give rise to intense infrared absorption bands. These bands are sensitive reporters of the electron density across the H-cluster, which can be addressed by infrared (IR) spectroscopy to follow redox and protonation changes at the cofactor during hydrogen turnover. Synthetic variation 
of the metal-bridging dithiolate ligand at the diiron site, as well as site-directed mutagenesis of amino acids, provides access to the proton pathways towards the cofactor. Quantum chemical calculations are employed to specifically assign IR bands to vibrational modes of the diatomic ligands and yield refined H-cluster structures.

Here, we provide an overview of recent research on $[\mathrm{FeFe}]$-hydrogenases with emphasis on experimental and computational infrared studies. We describe advances in attenuated total reflection Fourier-transform infrared spectroscopy (ATR FTIR) and protein film electrochemistry, as well as density functional theory (DFT) calculations. Key cofactor species are discussed in terms of molecular geometry, redox state, and protonation. ${ }^{13} \mathrm{CO}$ isotope editing is introduced as a tool to evaluate the cofactor geometry beyond the limits of protein crystallography. In particular, the role of proton-coupled electron transfer (PCET) in the generation of catalytically relevant redox species is addressed.

We propose that site-selective protonation of the H-cluster biases surplus electrons either to the [4Fe-4S] cluster or to the diiron site. Protonation of the $[4 \mathrm{Fe}-4 \mathrm{~S}]$ cluster prevents premature reduction at the diiron site and stabilizes a reactive, terminal hydride during rapid $\mathrm{H}_{2}$ conversion. The observed H-cluster species are assigned either to the catalytic cycle of hydrogen turnover or to reactions possibly involved in activity regulation and cellular $\mathrm{H}_{2}$ sensing. In the catalytic cycle of $[\mathrm{FeFe}]$-hydrogenases, a specific $\mathrm{H}$-cluster geometry is preserved that features a bridging $\mathrm{CO}$ ligand. PCET ensures redox potential balancing for two sequential cofactor reduction steps. Implementation of the concept of sequential PCET at a geometrically inert cofactor with tight control of electron and proton localization may lead to a novel generation of biomimetic catalysts for the production of $\mathrm{H}_{2}$ as a fuel. 


\section{Introduction}

Hydrogenases are ancient metalloenzymes that catalyze the reversible reduction of protons to molecular hydrogen $\left(2 \mathrm{H}^{+}+2 \mathrm{e}^{-} \rightleftharpoons \mathrm{H}_{2}\right)$ in all domains of life. ${ }^{1}$ While [Fe]-only hydrogenases are found in archaea exclusively, $[\mathrm{NiFe}]$-hydrogenases are common in both bacteria and archaea. ${ }^{2}$ $[\mathrm{FeFe}]$-hydrogenases have been isolated from bacteria and certain eukaryotes and represent the phylogenetically most recent class. ${ }^{3}$ With a reported $\mathrm{H}_{2}$ release activity of at least $1,000 \mathrm{H}_{2} \mathrm{~s}^{-1}$ and negligible electrochemical overpotential, the catalytic cofactor of [FeFe]-hydrogenases has inspired a wealth of synthetic complexes. ${ }^{4-7}$ This review covers recent developments in the understanding of hydrogen turnover in [FeFe]-hydrogenases with emphasis on in situ infrared spectroscopy.
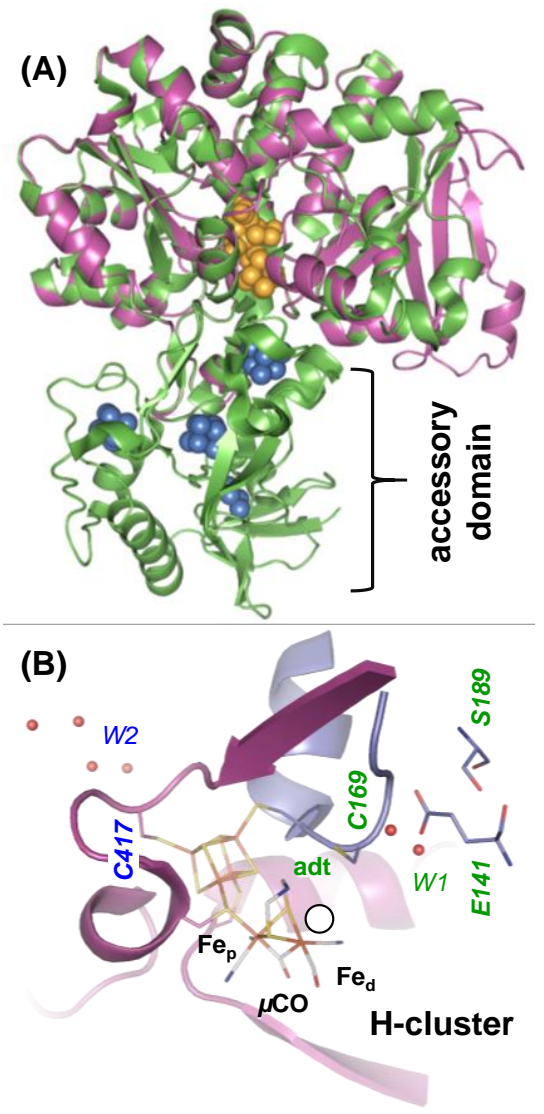
Figure 1. Protein fold and cofactors of [FeFe]-hydrogenases. (A) CPI crystal structure 4XDC including the iron-sulfur clusters of the accessory domain and the H-cluster (blue and orange spheres). The purple-colored overlay represents a homology model of HYDA1 apoprotein. (B) H-cluster binding site in CPI. The diiron complex binds to the [4Fe-4S] cluster by a single cysteine. Cysteine 169, water cluster W1, E141, and S189 (HYDA1 numbering) are part of the W1/adt proton transfer pathway towards $\mathrm{Fe}_{\mathrm{d}} \cdot{ }^{8-10}$ Cysteine 417 at the $[4 \mathrm{Fe}-4 \mathrm{~S}]$ cluster is a potential protonation site as part of proton transfer pathway W2.

The enzyme CPI from Clostridium pasteurianum represents the prototypical bacterial [FeFe]hydrogenase. ${ }^{11-13}$ Its accessory domain carries up to four iron-sulfur clusters that wire electrons from the protein surface to the active-site cofactor in the catalytic domain (Fig. 1A). The [FeFe]hydrogenase from the green alga Chlamydomonas reinhardtii (HYDA1) lacks the accessory domain and exclusively binds the catalytic cofactor, commonly denoted as H-cluster. ${ }^{14}$ The Hcluster consists of a [4Fe-4S] cluster covalently bound to the protein scaffold by four cysteine residues, one of which additionally binds the characteristic diiron site (Fig. 1B). The latter is equipped with one carbon monoxide $(\mathrm{CO})$ and one cyanide ligand $\left(\mathrm{CN}^{-}\right)$at each iron ion. Potential hydrogen bonding partners to the $\mathrm{CN}^{-}$ligands motivated an orientation of the diatomic ligands in the oxidized resting state (Hox) of the cofactor as shown in Fig. 1B. ${ }^{15,16}$ The third carbonyl is found in bridging position $(\mu \mathrm{CO})$ between proximal and distal iron ions $\left(\mathrm{Fe}_{\mathrm{p}}, \mathrm{Fe}_{\mathrm{d}}\right)$ and stabilizes an unoccupied, apical coordination site at $\mathrm{Fe}_{\mathrm{d}}$. In contrast to the octahedral ligand arrangement at $\mathrm{Fe}_{\mathrm{p}}$, the eclipsed, square pyramidal ligation at $\mathrm{Fe}_{\mathrm{d}}$ has inspired the term "rotated geometry". ${ }^{7}$ A fourth $\mathrm{CO}$ ligand binds to $\mathrm{Fe}_{\mathrm{d}}$ in $\mathrm{CO}$-inhibited enzyme. ${ }^{17-19}$ Because exogenous $\mathrm{CO}$ protects the enzymes against $\mathrm{O}_{2}$-induced deactivation and reversibly inhibits hydrogen turnover, $\mathrm{Fe}_{\mathrm{d}}$ is most likely the 
site of catalysis. ${ }^{20,21}$ The head group of the native dithiolate at the diiron site was identified as a secondary amine (adt, $\left.\left(\mathrm{SCH}_{2}\right)_{2} \mathrm{NH}\right)$ which serves as proton relay between $\mathrm{H}$-cluster and protein scaffold. $^{22}$ The generation of cofactor variants with unnatural dithiolate moieties by artificial maturation of $[\mathrm{FeFe}]$-hydrogenase has propelled site-specific studies on cofactor redox chemistry and protonation pathways (Fig. 2). ${ }^{23-25}$
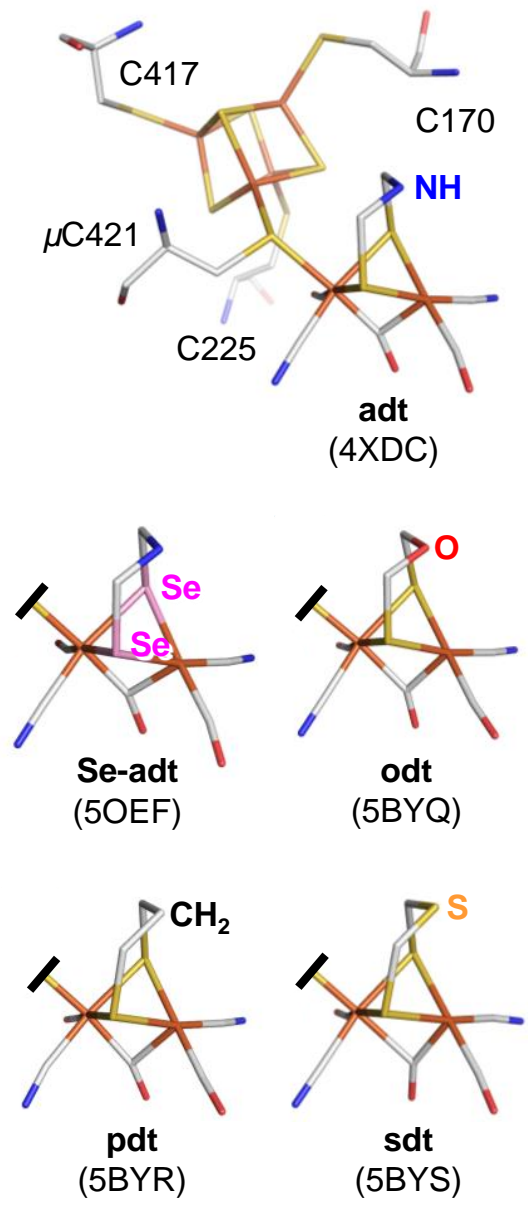

Figure 2. Crystallized H-cluster variants with different dithiolate moieties. The H-cluster binds to the protein fold via four cysteines and consists of a [4Fe-4S] cluster and the diiron site. The native dithiolate bridge $\left(\mathrm{adt},\left(\mathrm{SCH}_{2}\right)_{2} \mathrm{NH}\right)$ can be exchanged by in vitro maturation of hydrogenase apo-protein with synthetic diiron complexes including a oxodithiolate (odt, $\left.\left(\mathrm{SCH}_{2}\right)_{2} \mathrm{O}\right)$, sulfurdithiolate (sdt, $\left.\left(\mathrm{SCH}_{2}\right)_{2} \mathrm{~S}\right)$, or propanedithiolate moiety (pdt, $\left(\mathrm{SCH}_{2}\right)_{2} \mathrm{CH}_{2}$ ), 
as proven by crystal structures. ${ }^{13}$ Furthermore, ruthenium ${ }^{26}$ and selenide substitutions were reported..$^{27,28}$

\section{Quantitative Infrared Spectroscopy and Isotope Editing}

\subsection{ATR FTIR Spectroscopy}

Fourier-transform infrared (FTIR) spectroscopy is a key technique in the characterization of hydrogenases. ${ }^{17-19}[\mathrm{FeFe}]$-hydrogenases show characteristic IR bands that are unambiguously assigned to the $\mathrm{CO}$ and $\mathrm{CN}^{-}$ligands of the $\mathrm{H}$-cluster. The spectral features are sensitive to redox and protonation changes as well as cofactor geometry and protein environment. We have developed an experimental set-up that facilitates manipulating the steady-state equilibria between cofactor species in real time. This approach relies on the formation of protein films measured in attenuated total reflection configuration (ATR, Fig. 3A). The ATR FTIR setup allows for defined hydration of the protein film with an aerosol composed of gas and aqueous solvent. We were able to demonstrate that IR spectral changes can be quantified as a function of light and gas composition, ${ }^{29}$ proton and reactant concentration ${ }^{30-32}$, and electrochemical potential. ${ }^{33,34}$ Furthermore, this approach permits isotope exchange studies. ${ }^{29-35}$ 

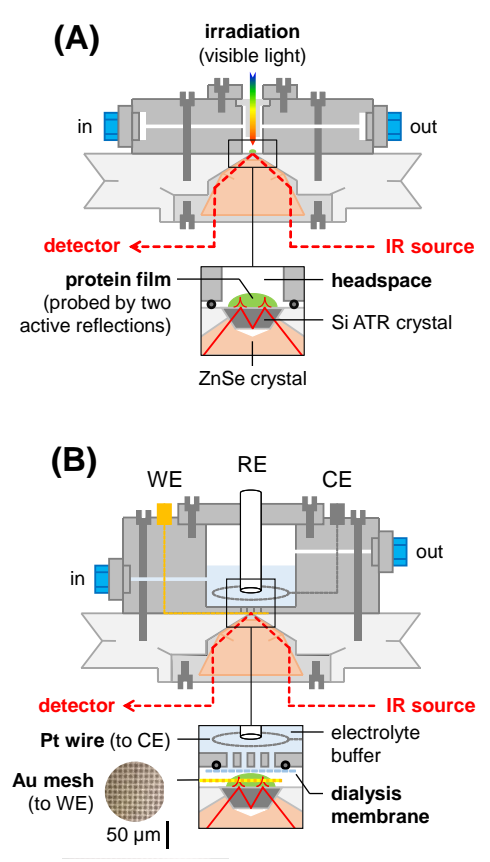

\section{Figure 3. Setup for in situ ATR FTIR spectroscopy and spectro-electrochemistry. (A)} Delivery of humidified gas (i.e. aerosol) to the protein film facilitates quantitative $\mathrm{pH}$ and reactant titrations, isotope editing, and irradiation experiments. (B) Modification of the silicon ATR crystal with a gold mesh electrode allows triggering redox changes. To protect the water soluble hydrogenase from dilution, a dialysis membrane covers the protein film. Legend: WE, working electrode; RE, reference electrode; CE, counter electrode.

To vary the electrochemical potential across the protein film, the ATR FTIR setup was modified based on a concept developed by Mäntele and coworkers. ${ }^{36}$ Instead of depositing the sample directly onto the ATR crystal, protein solution was injected into a mesoporous gold mesh in close contact to the crystal. The gold mesh serves as the working electrode in spectro-electrochemistry (Fig. 3B) and facilitates direct electron transfer so that external redox mediators are not required. ${ }^{33,34}$ Access to the electrolyte buffer allows adjusting $\mathrm{pH}$, reactant concentration, and gas composition. Figure 4 shows ATR FTIR spectro-electrochemical difference spectra for prominent 
H-cluster species that were obtained with our setup. The annotated cofactor species are introduced and discussed in the following sections. Their vibrational, electronic, and structural properties are summarized in ref. ${ }^{25}$.
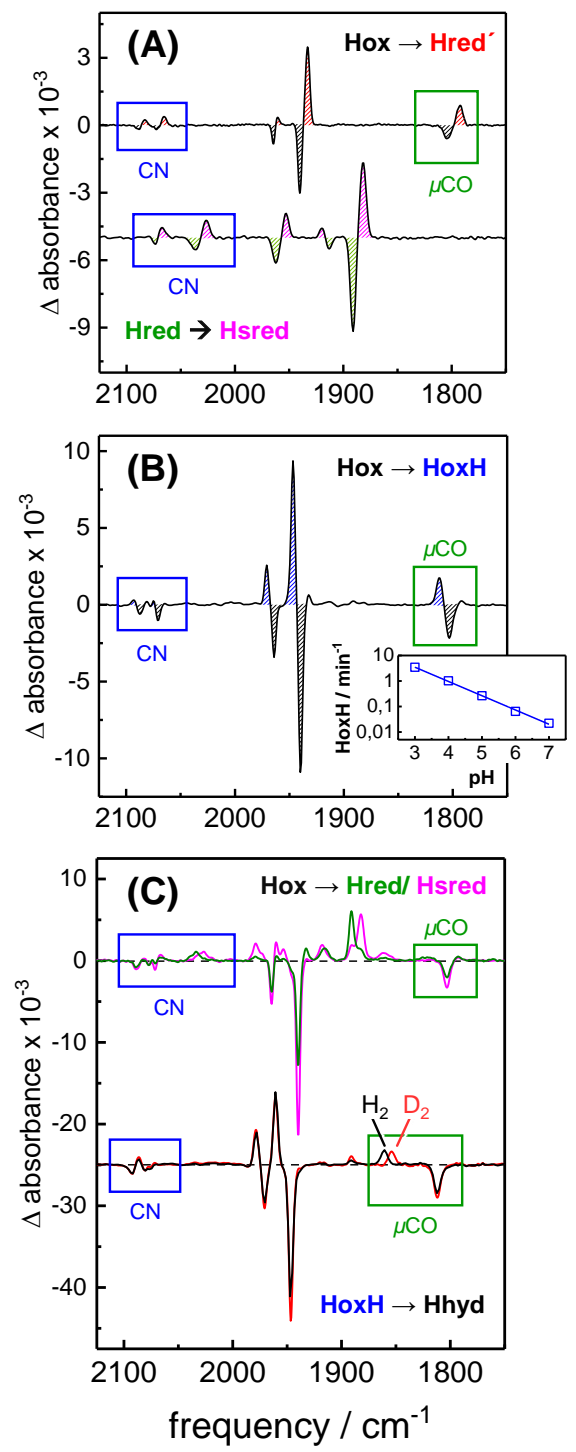

Figure 4. ATR FTIR difference spectra for native [FeFe]-hydrogenase. (A) Redox transitions Hox $\rightarrow$ Hred $^{\prime}(-350$ to $-450 \mathrm{mV}, \mathrm{pH}$ 9) and Hred $\rightarrow$ Hsred $(-650 \mathrm{mV}$ to $-750 \mathrm{mV}$ $\mathrm{pH}$ 6). The shift to lower frequencies in both traces is assigned to a reduction of the [4Fe-4S] cluster. (B) Transition Hox $\rightarrow$ HoxH upon acidification in presence of sodium dithionite (DT). Inset: correlation between $\mathrm{pH}$ and HoxH formation rate with $500 \mathrm{mM}$ DT. The shift to higher 
frequencies was attributed to a protonation of the $[4 \mathrm{Fe}-4 \mathrm{~S}]$ cluster. (C) In presence of $\mathrm{H}_{2}$, the H-cluster adopts different redox states. Enrichment of Hred (green) and Hsred (magenta) over Hox is observed at pH 6 whereas HoxH is converted to Hhyd at pH 4. Note the frequency down-shift of the $\mu \mathrm{CO}$ band when Hhyd accumulates under $\mathrm{D}_{2}$.

\subsection{Cofactor Geometry from Isotope Editing and DFT Calculations}

In the Hox state, $[\mathrm{FeFe}]-$ hydrogenases are very sensitive to $\mathrm{CO}$ inhibition. ${ }^{17-21}$ The fourth $\mathrm{CO}$ ligand at the cofactor causes significant vibrational coupling, which was employed for an evaluation of H-cluster geometries in the CO-inhibited state (Hox-CO) by ATR FTIR spectroscopy and density functional theory (DFT) calculations on whole-cofactor models. We developed a protocol for site-selective isotope editing and characterized all possible ${ }^{13} \mathrm{CO}$ labeling patterns of the H-cluster in Hox and Hox-CO. ${ }^{29}$ DFT yielded geometry-optimized cofactor structures and normal mode analysis provided the $\mathrm{CO} / \mathrm{CN}^{-}$IR frequencies of the ${ }^{13} \mathrm{CO}$ isotopomers for any conceivable ligand arrangement at the diiron site (about 200 structures considered). For Hox, DFT analysis confirmed the $\mathrm{CO} / \mathrm{CN}^{-}$ligand arrangement as previously suggested. ${ }^{11-13}$ In case of HoxCO, originally exogenous $\mathrm{CO}$ was modelled binding trans to $\mu \mathrm{CO}^{12}$, however our correlation analysis uniquely favored an apical $\mathrm{CN}^{-}$ligand. ${ }^{29}$ The DFT model further suggests a stabilization of the apical ligand by weak hydrogen-bonding to the adt-NH, which may be the reason why HYDA $1^{\text {pdt }}$ has not been shown to bind exogenous CO. ${ }^{37}$ These results highlight the structural flexibility of the H-cluster, in particular with respect to the diatomic ligand arrangement at the distal iron ion. The thermal motion of adjacent amino acids may be coupled to a rearrangement of equatorial $\mathrm{CN}^{-}$in $\mathbf{H o x}$ into an apical position in $\mathbf{H o x}-\mathbf{C O} .{ }^{38-40}$ 


\section{Proton-Coupled Electron Transfer at the H-cluster}

\subsection{Protonation of the $[4 \mathrm{Fe}-4 \mathrm{~S}]$ Cluster in the Oxidized State}

The IR bands of the oxidized H-cluster (Hox) are shifted to higher frequencies upon acidification in presence of a reductant (Fig. 4B). ${ }^{31}$ This observation tempted us to assume a protonated H-cluster species (HoxH). The transition is conserved in cofactor variant HYDA1 ${ }^{\text {pdt }}$ (Fig. 2), which excludes the bridgehead nitrogen of the native adt group as protonation site. DFT calculations were employed to explore all conceivable protonation sites at the H-cluster. Protonation at the sulfur atom of cysteine 417 , a terminal ligand of the [4Fe-4S] cluster, yielded superior agreement between the experimental and calculated IR frequencies of HoxH. These results suggested that protonation reactions at the $[4 \mathrm{Fe}-4 \mathrm{~S}]$ cluster may be involved in $[\mathrm{FeFe}]$-hydrogenase catalysis. ${ }^{31} \mathrm{~A}$ chain of water molecules in the cleft between accessory and catalytic domain possibly mediates proton transfer to the $[4 \mathrm{Fe}-4 \mathrm{~S}]$ cluster (W2 pathway, Fig. 5A). ${ }^{11-13}$
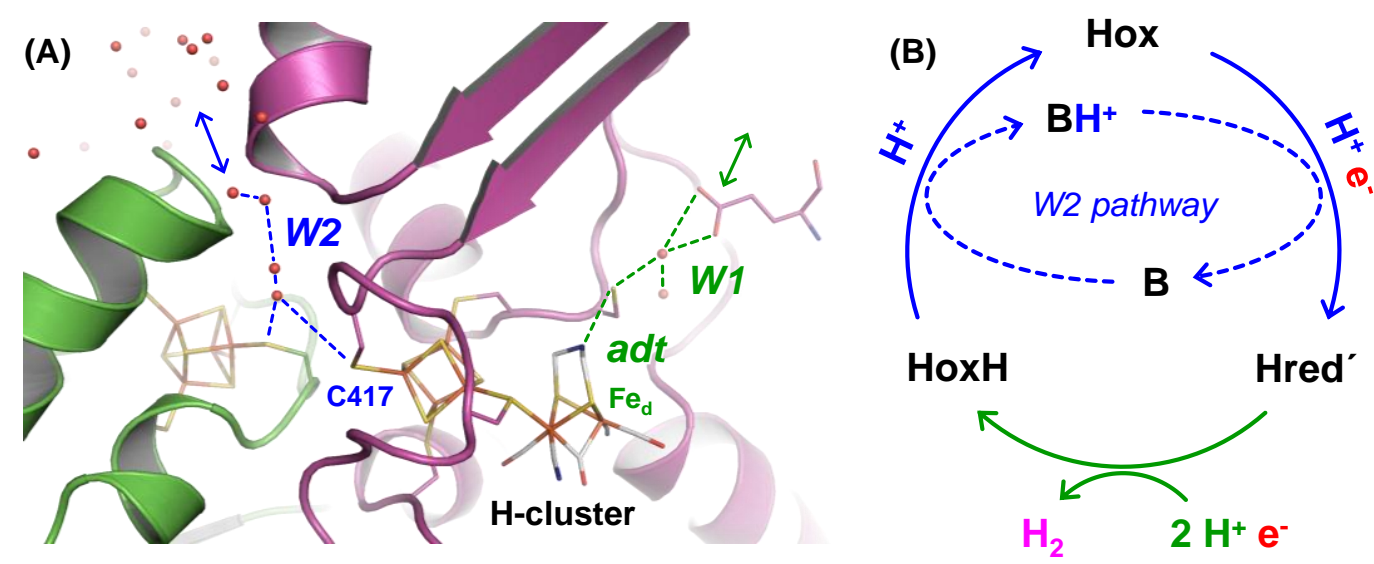

Figure 5. Enrichment of HoxH under turnover conditions. (A) Putative proton transfer paths W1/adt towards the diiron site (left branch, green) and W2 towards C417 of the [4Fe4S] cluster (right branch, blue) as found in CPI (4XDC). Both trajectories are conserved in all crystal structures. (B) PCET to the [4Fe-4S] cluster facilitates formation of Hred' from Hox 
and involves a near-by base B, e.g. a water molecule of W2. Hydrogen gas is released in a second PCET step (see Fig. 8 for details). Intervening re-protonation of B at low pH impairs deprotonation of the re-oxidized [4Fe-4S] cluster so that HoxH accumulates.

The role of reductant in the enrichment of the protonated, oxidized state is explained by placing HoxH at the end of the catalytic cycle (Fig. 5B). Starting with Hox, proton-coupled electron transfer (PCET) to the [4Fe-4S] cluster leads to formation of a one-electron reduced state (Hred', see Section 3.3). Subsequent loss of reducing equivalents via $\mathrm{H}_{2}$ release leaves the oxidized cofactor with a protonated $[4 \mathrm{Fe}-4 \mathrm{~S}]$ cluster. HoxH accumulates when the putative nearby base (B, possibly an adjacent water molecule of the W2 pathway) becomes re-protonated prior to $\mathrm{H}_{2}$ release $\left(\mathrm{BH}^{+}\right)$, i.e. at acidic $\mathrm{pH}$, so that the final deprotonation of the re-oxidized [4Fe-4S] cluster is impaired. ${ }^{31}$ Our assignment of HoxH provided the conceptual framework for an improved description of other redox species and represents a rare biological example of [4Fe-4S] cluster protonation. $^{41}$

\subsection{Reduction of the Diiron Site and Formation of a Bridging Hydride}

One-electron reduction of the Hox state yields two different cofactor species (Hred and Hred') with clearly deviating IR signatures (Fig. 4A). FTIR spectro-electrochemistry has demonstrated that the formation of Hred involves both an electron transfer and a protonation event. ${ }^{42}$ The altered IR signature indicates that the H-cluster undergoes significant structural rearrangements in Hred, but the underlying cofactor geometry is much debated. In comparison to Hox, an early crystal structure of $\mathrm{H}_{2}$-reduced [FeFe]-hydrogenase DDH showed subtle differences in electron density between the iron centers of the diiron site. ${ }^{43}$ This was interpreted as a H-cluster geometry with a 
"semi-bridging" CO ligand and tentatively assigned to Hred (Fig. 6A, model 2). It is now known that $[\mathrm{FeFe}]$-hydrogenases can adopt a number of different reduced states in presence of $\mathrm{H}_{2}$ (see Sections 3.3 and 3.4), some of which show a $\mu$ CO ligand easily compatible with the proposed DDH cofactor geometry. ${ }^{30,31}$ Therefore, the redox state of the crystallized enzyme remains ambiguous and further crystallographic studies on reduced species are urgently required.

In analogy to [NiFe]-hydrogenases ${ }^{44}$ and synthetic diiron complexes ${ }^{5-7}$, the H-cluster structure has inspired discussions on the possibility of a Fe-Fe bridging hydride $(\mu \mathrm{H})$ as reactive species in hydrogen turnover (Fig. 6A, model 3). Experimental and theoretical considerations suggested that such a cofactor geometry could be fairly stable; however, it would likely be less reactive than a structure with a terminal hydride. ${ }^{45-47}$ Evidence for a $\mu \mathrm{H}$ in a reduced $\mathrm{H}$-cluster species came from X-ray absorption and emission spectroscopy in combination with DFT. ${ }^{48,49}$ 


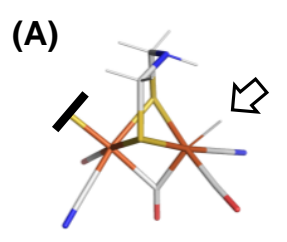

model 1

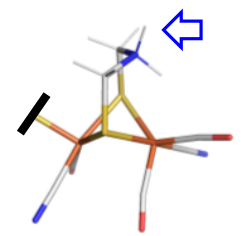

model 2

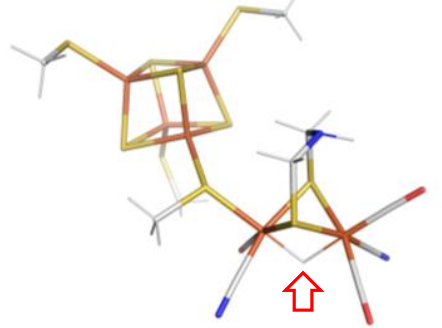

model 3

(B)

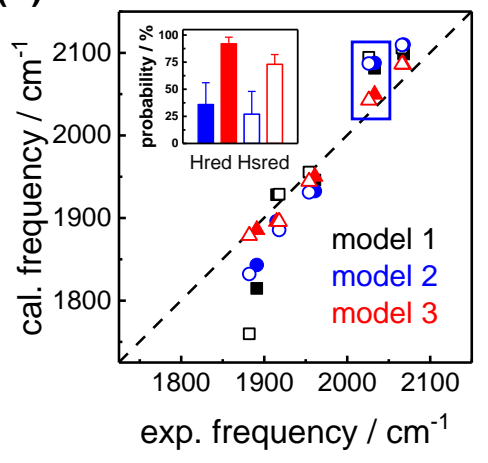

Figure 6. Evaluation of different $\mathrm{H}$-cluster geometries for the reduced states Hred and Hsred. (A) Considered models 1 - 3 differ with respect to hydrogen species binding (arrows) and Fe-Fe bridging motifs. (B) Calculated IR frequencies from DFT of the $\mathrm{CO} / \mathrm{CN}^{-}$ligands plotted versus the experimental values. Hred (open symbols) and Hsred (solid symbols) structures with a $\mu \mathrm{H}$ (model 3) show IR frequencies in best agreement with ideal correlation (dashed line) and reproduce the large $\mathrm{CN}^{-}$frequency gap (blue box). Calculated IR data was corrected for theory-inherent deviations. Inset: apparent probability for models 2 and 3 derived from statistical analyses. 
We have reported a systematic evaluation of IR frequencies of Hred and Hsred by DFT in combination with ${ }^{13} \mathrm{CO}$ isotope editing and ATR FTIR spectro-electrochemistry. ${ }^{34}$ The twoelectron reduced Hsred state differs from Hred in an additional reduction of the [4Fe-4S] cluster but the similar IR signatures suggest an overall similar cofactor geometry (Section 3.4). ${ }^{50}$ Correlation of experimental and computational IR signatures for three different Hred and Hsred geometries as suggested earlier (Fig. 6B) clearly favors a model of the H-cluster with a reduced diiron site, an apical $\mathrm{CO}$ ligand at $\mathrm{Fe}_{\mathrm{d}}$, a singly protonated adt group, and a $\mu \mathrm{H}$ in $\mathrm{Fe}-\mathrm{Fe}$ bridging position. $^{34}$

A recent study on the [FeFe]-hydrogenase from C. acetobutylicum (CAI) has identified a Hred-like state with a $\mu \mathrm{CO}$ band that converts into Hred upon transition from $15 \mathrm{~K}$ to $260 \mathrm{~K} .{ }^{51}$ Apparently, changes in cofactor geometry are impaired under cryogenic conditions and allow trapping the Hred-like intermediate. Elevated temperatures ("biological conditions") facilitate ligand reorientation and proton transfer, which according to our data results in $\mu \mathrm{H}$ formation in Hred. ${ }^{34}$ Interestingly, the regulatory [FeFe]-hydrogenase from T. maritima shows a Hred-like state similar to CAI even under biological conditions $(290 \mathrm{~K}) .{ }^{52}$ However, this enzyme differs from "standard" $[\mathrm{FeFe}]$-hydrogenases by several amino acid exchanges around the cofactor, precluding a direct comparison to CAI.

\subsection{Site-selective Reduction and Protonation at the H-cluster}

Originally, the one-electron reduced state Hred' has been characterized in cofactor variant HYDA $1^{\text {pdt }}$ and was observed in native $[\mathrm{FeFe}]$-hydrogenases later on as well. ${ }^{37,42}$ Under reducing conditions, Hred' is formed at alkaline $\mathrm{pH}$ preferentially whereas Hred dominates at more acidic pH values. ${ }^{31}$ The Hox $\rightarrow$ Hred $^{\prime}$ conversion is characterized by a reduction of the [4Fe-4S] cluster, 
which causes a small shift to lower frequencies of the $\mathrm{CO} / \mathrm{CN}^{-}$bands (Fig. 4A). Furthermore, the IR signature clearly indicates that the H-cluster in Hred' carries a $\mu \mathrm{CO}$ ligand. ${ }^{34}$ Spectroelectrochemical studies have revealed that the midpoint potentials of the Hox $\rightarrow$ Hred and Hox

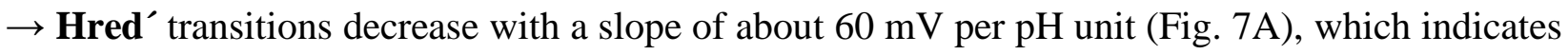
that both processes involve PCET. ${ }^{33,42}$ Similar to HoxH, correlation analysis of experimental and computational IR data of Hred' favored a protonation at cysteine 417 of the [4Fe-4S] cluster. ${ }^{31}$
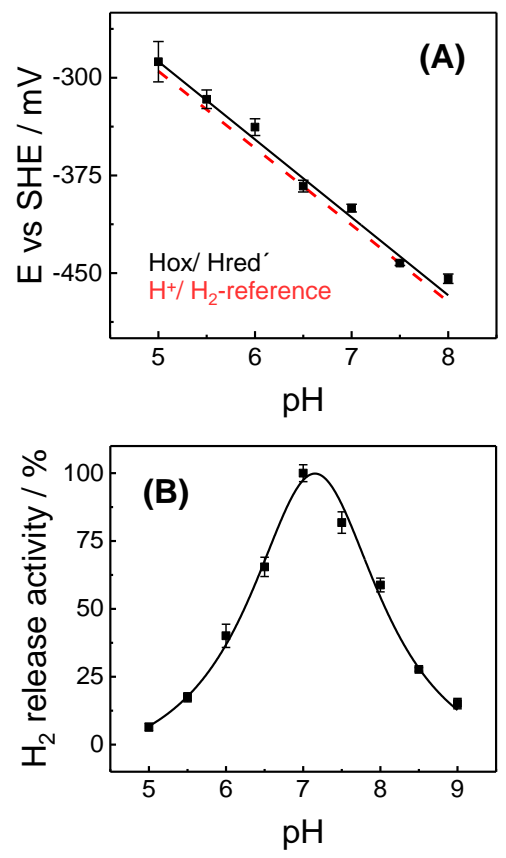

Figure 7. Proton-coupled electron transfer at the H-cluster. (A) Pourbaix diagram showing the $\mathrm{pH}$-dependence of the midpoint potential of the $\mathbf{H o x} \rightarrow$ Hred' $^{\prime}$ reduction. Linear regression (black line) with a slope of $\sim 60 \mathrm{mV} / \mathrm{pH}$ indicates a PCET reaction at similar potentials as the $\mathrm{H}^{+} / \mathrm{H}_{2}$ redox couple (red dashes). (B) $\mathrm{pH}$-dependence of $\mathrm{H}_{2}$ release activity for HYDA1 in a solution assay. The activity decrease for $\mathrm{pH}<7$ suggests accumulation of catalytically less reactive $\mathrm{H}$-cluster species. 
Our experimental and theoretical explorations consistently suggest that a bridging hydride is bound at the reduced diiron site in Hred $^{34}$ whereas the $[4 \mathrm{Fe}-4 \mathrm{~S}]$ cluster is reduced and protonated in Hred ${ }^{\prime}{ }^{31,33}$ Furthermore, the observation that alkaline conditions favor Hred' and acidic $\mathrm{pH}$ values promote Hred suggests that the velocities of $[4 \mathrm{Fe}-4 \mathrm{~S}]$ cluster and diiron site protonation are intrinsically different and vary with $\mathrm{pH} .{ }^{31,42}$ Selective proton transfer apparently biases the surplus electron to either the diiron site or the $[4 \mathrm{Fe}-4 \mathrm{~S}]$ cluster, controlling cofactor geometry as well as enzymatic activity. This model can explain the bell-shaped $\mathrm{pH}$-dependence of $\mathrm{H}_{2}$ release activity of [FeFe]-hydrogenases (Fig. 7B), which has remained inconclusive for a long time. ${ }^{53}$ The activity increase from alkaline to neutral $\mathrm{pH}$ can be explained by an increase of reactant concentration (i.e., protons) while the activity decrease towards more acidic $\mathrm{pH}$ may be due to accumulation of catalytically less reactive species. These findings suggest that catalytic hydrogen turnover coincides with a Hox-like $\mathrm{H}$-cluster geometry $(\mu \mathrm{CO})$ that is preserved in Hred' ${ }^{31}$ The declined $\mathrm{H}_{2}$ release activity at acidic $\mathrm{pH}$ then would reflect $\mathrm{H}$-cluster species with an altered cofactor geometry (i.e. $\mu \mathrm{H}$ in Hred and Hsred).

\subsection{Reduction of the H-cluster by Two Electrons}

In the so-called super-reduced state (Hsred), the H-cluster is characterized by a reduction of both diiron site and $[4 \mathrm{Fe}-4 \mathrm{~S}]$ cluster. ${ }^{50}$ The IR signature is similar to Hred and the band shifts mirror the frequency difference between Hox and Hred' (Fig. 4A). Accordingly, our analyses favor similar cofactor geometries in Hred and Hsred. ${ }^{34}$ An additional two-electron reduced H-cluster species was identified in amino acid variants of proton transfer path W1. ${ }^{54,55}$ In comparison to Hox, this state shows a pronounced frequency up-shift of all cofactor bands, indicative of a decrease of electron density at the diiron site (Fig. 4C). The small yet significant frequency down-shift of the 
$\mu \mathrm{CO}$ band in deuterated enzyme supports that this state carries a terminal hydride and has therefore been termed Hhyd ${ }^{30,55}$ Mössbauer spectroscopy revealed a midpoint potential of $-430 \mathrm{mV}$ (pH 8) for the Hox $\rightarrow$ Hhyd transition, in good agreement with the $\mathrm{H}^{+} / \mathrm{H}_{2}$ reference potential. ${ }^{55}$ This is convincing evidence that a species similar to Hhyd is involved in hydrogen turnover.

We have studied Hhyd by ATR FTIR and DFT in order to assign cofactor geometry and protonation state. The enrichment of Hhyd in catalytically competent, native HYDA1 was monitored in response to isotope editing, gas exchange, and $\mathrm{pH}$ titration. ${ }^{30}$ At acidic $\mathrm{pH}, \mathbf{H o x H}$ can be converted to Hhyd in presence of $\mathrm{H}_{2}$ or $\mathrm{D}_{2}$ (Fig. 4C). The direct conversion suggests a protonated [4Fe-4S] cluster in Hhyd, which is favored by X-ray spectroscopy and DFT as well. ${ }^{32}$ The accumulation of Hhyd under turnover conditions may be based on a similar re-protonation of the adjacent base at low $\mathrm{pH}$ as suggested for HoxH (Fig. 5B). In summary, the available data for Hhyd favor a Hox-like H-cluster geometry $(\mu \mathrm{CO})$ with an apical hydride at $\mathrm{Fe}_{\mathrm{d}}$ and suggest a protonated $[4 \mathrm{Fe}-4 \mathrm{~S}]$ cluster.

\section{The Molecular Proceedings of Hydrogen Turnover}

Various proposals for the catalytic mechanism of [FeFe]-hydrogenases have been put forward in recent years. ${ }^{30,33,38,42,55,56}$ A prominent mechanistic scheme was devised and continuously refined by Lubitz and coworkers. ${ }^{26,42,57}$ In their present model, starting from Hox, a Hred-like intermediate $^{42}$ is formed upon electron transfer to the diiron site and concerted proton transfer to the adt group. Electron transfer to the $[4 \mathrm{Fe}-4 \mathrm{~S}]$ cluster leads to an Hsred-like species ${ }^{50}$ before proton transfer from the adt group to $\mathrm{Fe}_{\mathrm{d}}$ initiates the formation of Hhyd ${ }^{57}$ Upon delivery of a second proton, the hydride species spontaneously reacts to form $\mathrm{H}_{2}$, which leaves the active site and restores the oxidized $\mathrm{H}$-cluster. This model and related proposals ${ }^{45,54-56}$ critically involve a 
protonated adt group for Hred/Hsred and (in most cases) hypothetical intermediates. ${ }^{57}$ Our data clearly disfavor adt protonation in any H-cluster intermediate ${ }^{31-34}$, including Hhyd as supported by recent nuclear inelastic scattering data. ${ }^{58}$ Furthermore, the proposed geometry of the reduced Hcluster is barely compatible with the experimental IR signature of Hred and Hsred. ${ }^{34}$ Including only experimentally and computationally verified intermediates, we arrive at an alternative reaction scheme that and emphasizes the role of PCET in biological hydrogen turnover (Fig. 8). In the future, spectroscopy with sub-turnover time resolution will help to distinguish whether a particular intermediate is involved in the catalytic cycle. ${ }^{25}$ Application of such approaches to [FeFe]hydrogenases is challenging due to the lack of intrinsic means to trigger and synchronize catalytic activity, but recent progress in the field is promising. ${ }^{59-62}$

We briefly outline the key features of our model in the following. The diiron site of the oxidized H-cluster (Hox) features an open coordination site trans to $\mu \mathrm{CO}$ at $\mathrm{Fe}_{\mathrm{d}}$ as opposed to the symmetrical geometry of many synthetic diiron compounds that lack a bridging carbonyl. ${ }^{5-7}$ The Hox-like geometry is considered prerequisite for rapid hydrogen turnover that proceeds via a terminal hydride whereas ligand rearrangement at the diiron site and $\mu \mathrm{H}$ binding has been considered to be incompatible with the experimentally observed rate of catalysis. ${ }^{45-47}$ We propose that the initial site of protonation determines whether a Hox-like geometry is maintained or an altered geometry is acquired (Fig. 8). 


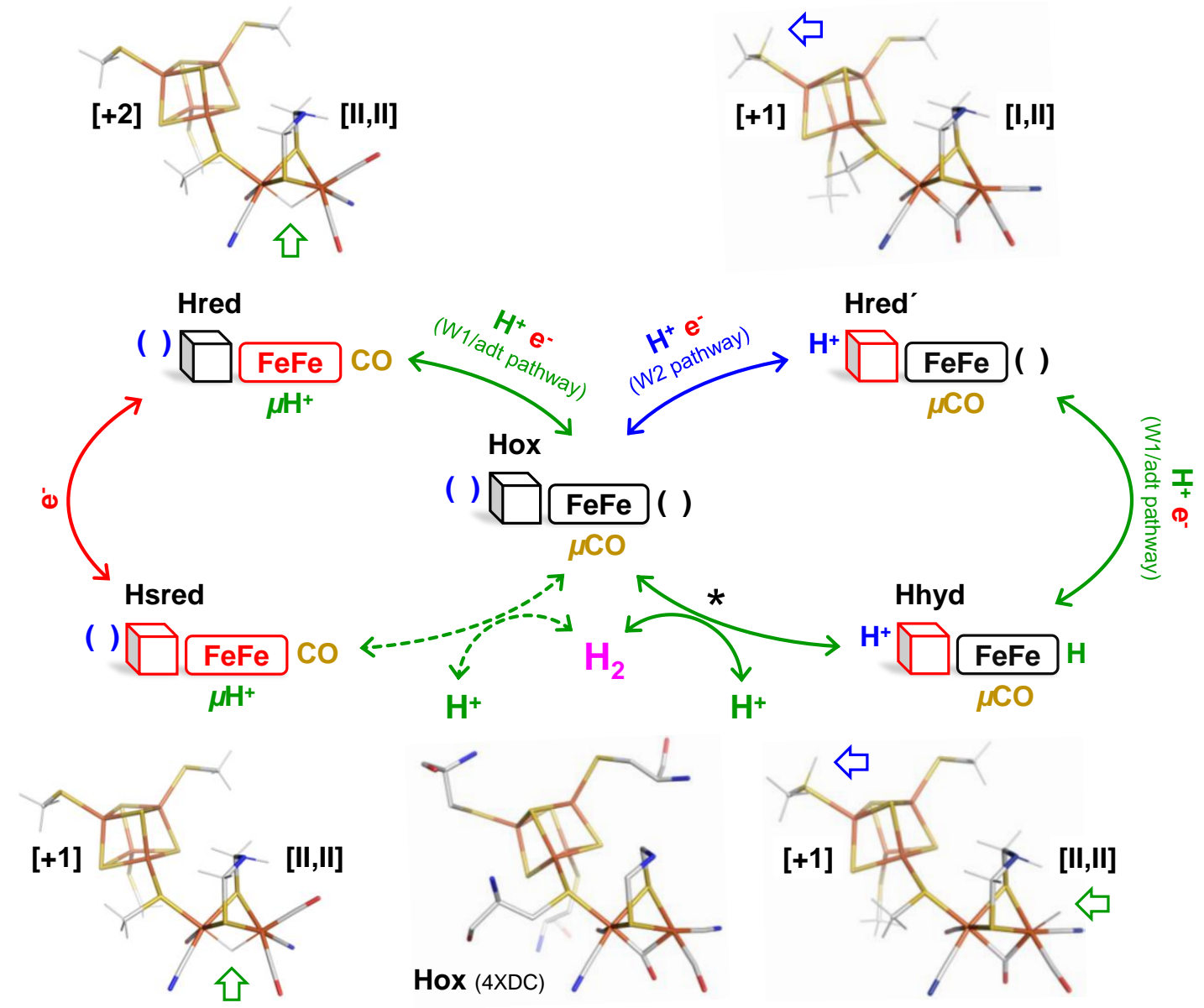

Figure 8. Catalysis and regulation at the H-cluster of [ $\mathrm{FeFe}]$-hydrogenases. In the schematic representation of the H-cluster the dithiolate group was omitted. Red color denotes the location of surplus charge. Model structures were derived from DFT based on Hox crystal structure 4XDC. Formal redox state assignments of the H-cluster sub-complexes are indicated. Left Branch: PCET first to the diiron site via the W1/adt proton transfer pathway (green, i.e. at acidic $\mathrm{pH})$ facilitates formation of $\mathrm{H}$-cluster species with an altered cofactor geometry $(\mu \mathrm{H})$, possibly involved in the regulation of enzyme activity and hydrogen metabolism. Protonation of the [4Fe-4S] cluster in Hsred is not uniquely implied but compatible with our data. Right branch: The catalytic cycle of rapid hydrogen conversion exclusively involves intermediates with a Hox-like cofactor geometry. PCET first to the [4Fe-4S] cluster via the W2 pathway 
(blue, i.e. at alkaline $\mathrm{pH}$ ) preserves the $\mu \mathrm{CO}$ ligand and facilitates charge compensation in the first redox step. HoxH is potentially involved as a transient intermediate $(*)$ between Hhyd and Hox as shown in Fig. 5B.

Upon injection of the first electron, proton transfer via the W1/adt pathway dominates at low $\mathrm{pH}$ (left branch in Fig. 8). ${ }^{31}$ This leads to ligand rearrangement at the reduced diiron site and $\mu \mathrm{H}$ binding (Hred). Injection of a second electron reduces the [4Fe-4S] cluster and preserves the altered cofactor geometry (Hsred). ${ }^{34}$ As detailed above, it might be possible to release $\mathrm{H}_{2}$ at this stage $^{42,57,63}$, however the accumulation of Hred and Hsred under acidic conditions rather coincides with a decrease in catalytic activity. A pH-dependent activity regulation of [FeFe]-hydrogenases may represent an evolutionary adaption to varying metabolic conditions in the cell. ${ }^{64}$ Interestingly, regulatory $[\mathrm{FeFe}]$-hydrogenases have been shown to accumulate Hred and Hsred even at alkaline $\mathrm{pH}^{52}$ In analogy to regulatory [NiFe]-hydrogenases, it is tempting to speculate that only the longlived $\mu \mathrm{H}$ geometry can initiate protein structural changes, i.e. for signal transduction via the PAS domain of sensory [FeFe]-hydrogenases. ${ }^{65,66}$ These considerations imply that the $\mu \mathrm{H}$ cofactor states may play viable roles in enzyme activity regulation and $\mathrm{H}_{2}$ sensing. In the future, it needs to be clarified whether catalysis and regulation are general features of [FeFe]-hydrogenases or mutually exclusive.

For protonation of the H-cluster via the W2 pathway (right branch in Fig. 8), the first electron is biased to the $[4 \mathrm{Fe}-4 \mathrm{~S}]$ cluster (Hred'). ${ }^{33}$ This prevents premature reduction of the diiron site and stabilizes the Hox-like $\mathrm{H}$-cluster geometry by impeding $\mathrm{CO}$ ligand rearrangement and $\mu \mathrm{H}$ binding. ${ }^{31}$ Subsequently, PCET to the diiron site via the W1/adt pathway forms Hhyd with a terminal hydride. Catalytic protons are supplied only in the second reduction step and lead to an 
activated cofactor that readily reacts with a second proton to release $\mathrm{H}_{2} \cdot{ }^{30,54} \mathbf{H o x}$ is then regained via HoxH deprotonation and proton release to the W2 pathway (compare Fig. 5A). In line with earlier suggestions ${ }^{38}$, this catalytic cycle involves only intermediates with a Hox-like cofactor geometry as a prerequisite for rapid $\mathrm{H}_{2}$ conversion.

In conclusion, $[\mathrm{FeFe}]$-hydrogenases seem to exploit sophisticated mechanisms to discriminate hydrogen conversion from regulatory functions. Site-selective PCET stabilizes the Hox-like Hcluster geometry that facilitates rapid hydrogen turnover. The redox partners of [FeFe]hydrogenases are single-electron donors so that the two successive reduction steps have to proceed at a similar redox potential. ${ }^{2}$ This problem has been elegantly solved by initial PCET to the [4Fe4S] cluster, which is expected to level the redox potential for subsequent PCET to the diiron site. A similar mechanism is realized in the water oxidation catalyst of photosynthesis. ${ }^{67}$ The siteselective proton/electron management at the catalytic cofactor is key to rapid and reversible $\mathrm{H}_{2}$ conversion by $[\mathrm{FeFe}]-$ hydrogenases. Adopting this principle by incorporating protonable redox species in the vicinity of the catalytic metal site may lead to improved synthetic hydrogen conversion catalysts. ${ }^{68}$

\section{Acknowledgements}

STS thanks Joachim Heberle for long lasting support and scientific independence at Freie Universität Berlin. $\mathrm{MH}$ thanks the Bundesministerium für Bildung und Forschung for financial support within the Röntgen-Angström Cluster (grant 05K14KE1). We deeply appreciate the scientific and intellectual input of our colleagues and collaboration partners, in particular Thomas Happe, Martin Winkler, and Ulf-Peter Apfel (Ruhr-Universität Bochum) as well as Moritz Senger and Stefan Mebs (Freie Universität Berlin). 


\section{Biographical Information}

Sven T. Stripp studied Chemistry and Biology at Ruhr-Universität Bochum (Germany). He graduated in Biology and Biotechnology (with Thomas Happe) and received his Ph.D. in 2010. Afterwards, he moved to Freie Universität Berlin for post-doctoral studies on surface-enhanced vibrational spectroscopy. Since 2014, he is a group leader in the Department of Experimental Physics. His research interests are bioinorganic chemistry and in situ infrared spectroscopy.

Michael Haumann studied Biology at Universität Osnabrück (Germany). He graduated in Biophysics (with W. Junge) and received his Ph.D in 1996. After postdoctoral research (e.g. with H. Dau, Berlin) he obtained his Habilitation in Experimental Physics at Freie Universität Berlin in 2004. Since then he is working as an Assistant Professor (Privatdozent) at the Department of Experimental Physics, heading the Biophysics of Metalloenzymes group. His main research interests are metalloenzymes, small molecule activation, X-ray spectroscopy, and quantum chemistry.

\section{References}

(1) Lubitz, W.; Ogata, H.; Ru, O.; Reijerse, E. Hydrogenases. Chem. Rev. 2014, 114, 40814148 .

(2) Vignais, P. M.; Billoud, B. Occurrence, Classification, and Biological Function of Hydrogenases: An Overview. Chem. Rev. 2007, 107 (10), 4206-4272.

(3) Stripp, S. T.; Happe, T. How Algae Produce Hydrogen - News from the Photosynthetic Hydrogenase. Dalt. Trans. 2009, 45, 9960-9969. 
(4) Vincent, K. A.; Parkin, A.; Armstrong, F. A. Investigating and Exploiting the Electrocatalytic Properties of Hydrogenases. Chem. Rev. 2007, 107 (10), 4366-4413.

(5) Tard, C.; Pickett, C. J. Structural and Functional Analogues of the Active Sites of the [Fe], [NiFe]-, and [FeFe]-Hydrogenases. Chem. Rev. 2009, 109 (6), 2245-2274.

(6) Schilter, D.; Camara, J. M.; Huynh, M. T.; Hammes-Schiffer, S.; Rauchfuss, T. B. Hydrogenase Enzymes and Their Synthetic Models: The Role of Metal Hydrides. Chem. Rev. 2016, 116 (15), 8693-8749.

(7) Singleton, M. L.; Bhuvanesh, N.; Reibenspies, J. H.; Darensbourg, M. Y. Synthetic Support of de Novo Design: Sterically Bulky [FeFe]-Hydrogenase Models. Angew. Chemie Int. Ed. 2008, 47 (49), 9492-9495.

(8) Long, H.; King, P. W.; Chang, C. H. Proton Transport in Clostridium Pasteurianum [FeFe] Hydrogenase I: A Computational Study. J. Phys. Chem. B 2014, 118 (4), 890-900.

(9) Ginovska-Pangovska, B.; Ho, M.-H.; Linehan, J. C.; Cheng, Y.; Dupuis, M.; Raugei, S.; Shaw, W. J. Molecular Dynamics Study of the Proposed Proton Transport Pathways in [FeFe]-Hydrogenase. Biochim. Biophys. Acta 2014, 1837 (1), 131-138.

(10) Cornish, A. J.; Ginovska, B.; Thelen, A.; Da Silva, J. C. S.; Soares, T. A.; Raugei, S.; Dupuis, M.; Shaw, W. J.; Hegg, E. L. Single-Amino Acid Modifications Reveal Additional Controls on the Proton Pathway of [FeFe]-Hydrogenase. Biochemistry 2016, 55 (22), 3165-3173.

(11) Peters, J. W.; Lanzilotta, W. N.; Lemon, B. J.; Seefeldt, L. C. X-Ray Crystal Structure of the Fe-Only Hydrogenase (CpI) from Clostridium Pasteurianum to 1.8 Angstrom Resolution. Science 1998, 282 (5395), 1853-1858. 
(12) Lemon, B. J.; Peters, J. W. Binding of Exogenously Added Carbon Monoxide at the Active Site of the Iron-Only Hydrogenase (CpI) from Clostridium Pasteurianum. Biochemistry 1999, 38 (40), 12969-12973.

(13) Esselborn, J.; Muraki, N.; Klein, K.; Engelbrecht, V.; Metzler-Nolte, N.; Apfel, U.-P.; Hofmann, E.; Kurisu, G.; Happe, T. A Structural View of Synthetic Cofactor Integration into [FeFe]-Hydrogenases. Chem. Sci. 2016, 7, 959-968.

(14) Winkler, M.; Esselborn, J.; Happe, T. Molecular Basis of [FeFe]-Hydrogenase Function: An Insight into the Complex Interplay between Protein and Catalytic Cofactor. Biochim. Biophys. Acta 2013, 1827 (8-9), 974-985.

(15) Nicolet, Y.; Piras, C.; Legrand, P.; Hatchikian, C. E.; Fontecilla-Camps, J. C. Desulfovibrio Desulfuricans Iron Hydrogenase: The Structure Shows Unusual Coordination to an Active Site Fe Binuclear Center. Structure 1999, 7 (1), 13-23.

(16) Lampret, O.; Adamska-Venkatesh, A.; Konegger, H.; Wittkamp, F.; Apfel, U.-P.; Reijerse, E. J.; Lubitz, W.; Rü, O.; Happe, T.; Winkler, M. Interplay between CN Ligands and the Secondary Coordination Sphere of the H-Cluster in [FeFe]-Hydrogenases. J. Am. Chem. Soc. 2017, 139, 18222-18230.

(17) De Lacey, A. L.; Stadler, C.; Cavazza, C.; Hatchikian, E. C.; Fernandez, V. M. FTIR Characterization of the Active Site of the Fe-Hydrogenase from Desulfovibrio Desulfuricans. J. Am. Chem. Soc. 2000, 122 (45), 11232-11233.

(18) Chen, Z.; Lemon, B. J.; Huang, S.; Swartz, D. J.; Peters, J. W.; Bagley, K. A. Infrared Studies of the CO-Inhibited Form of the Fe-Only Hydrogenase from Clostridium Pasteurianum I: Examination of Its Light Sensitivity at Cryogenic Temperatures $\uparrow$. 
Biochemistry 2002, 41 (6), 2036-2043.

(19) Roseboom, W.; De Lacey, A. L.; Fernandez, V. M.; Hatchikian, E. C.; Albracht, S. P. J. The Active Site of the [FeFe]-Hydrogenase from Desulfovibrio Desulfuricans. II. Redox Properties, Light Sensitivity and CO-Ligand Exchange as Observed by Infrared Spectroscopy. J. Biol. Inorg. Chem. 2006, 11 (1), 102-118.

(20) Stripp, S. T.; Goldet, G.; Brandmayr, C.; Sanganas, O.; Vincent, K. A.; Haumann, M.; Armstrong, F. A.; Happe, T. How Oxygen Attacks [FeFe] Hydrogenases from Photosynthetic Organisms. Proc. Natl. Acad. Sci. U. S. A. 2009, 106 (41), 17331-17336.

(21) Goldet, G.; Brandmayr, C.; Stripp, S. T.; Happe, T.; Cavazza, C.; Fontecilla-Camps, J. C.; Armstrong, F. A. Electrochemical Kinetic Investigations of the Reactions of [FeFe]Hydrogenases with Carbon Monoxide and Oxygen: Comparing the Importance of Gas Tunnels and Active-Site Electronic/redox Effects. J. Am. Chem. Soc. 2009, 131 (41), 14979-14989.

(22) Silakov, A.; Wenk, B.; Reijerse, E.; Lubitz, W. 14N HYSCORE Investigation of the HCluster of [FeFe] Hydrogenase: Evidence for a Nitrogen in the Dithiol Bridge. Phys. Chem. Chem. Phys. 2009, 11 (31), 6553-6554.

(23) Berggren, G.; Adamska-Venkatesh, A.; Lambertz, C.; Simmons, T. R.; Esselborn, J.; Atta, M.; Gambarelli, S.; Mouesca, J.-M.; Reijerse, E. J.; Lubitz, W.; Happe, T.; Artero, V.; Fontecave, M. Biomimetic Assembly and Activation of [FeFe]-Hydrogenases. Nature 2013, 499 (7456), 66-69.

(24) Esselborn, J.; Lambertz, C.; Adamska-Venkatesh, A.; Simmons, T.; Berggren, G.; Noth, J.; Siebel, J. F.; Hemschemeier, A.; Artero, V.; Reijerse, E.; Fontecave, M.; Lubitz, W.; 
Happe, T. Spontaneous Activation of [FeFe]-Hydrogenases by an Inorganic [2Fe] Active Site Mimic. Nat. Chem. Biol. 2013, 9, 607-609.

(25) Wittkamp, F.; Senger, M.; Stripp, S. T.; Apfel, U.-P. [FeFe]-Hydrogenases: Recent Developments and Future Perspectives. Chem. Commun. 2018, 54, 5934-5942.

(26) Sommer, C.; Richers, C. P.; Lubitz, W.; Rauchfuss, T. B.; Reijerse, E. J. A [RuRu] Analogue of an [FeFe]-Hydrogenase Traps the Key Hydride Intermediate of the Catalytic Cycle Angewandte. Angew. Chemie Int. Ed. 2018, 57, 5429-5432.

(27) Noth, J.; Esselborn, J.; Güldenhaupt, J.; Brünje, A.; Sawyer, A.; Apfel, U.-P.; Gerwert, K.; Hofmann, E.; Winkler, M.; Happe, T. [FeFe]-Hydrogenase with Chalcogenide Substitutions at the H-Cluster Maintains Full H2 Evolution Activity. Angew. Chemie Int. Ed. 2016, 55, 8396-8400.

(28) Kertess, L.; Wittkamp, F.; Sommer, C.; Esselborn, J.; Rüdiger, O.; Reijerse, E.; Hofmann, E.; Lubitz, W.; Winkler, M.; Happe, T.; Apfel, U.-P. Chalcogenide Substitution in the [2Fe]-Cluster of [FeFe]-Hydrogenases Conserves High Enzymatic Activity. Dalt. Trans. 2017, 46, 16947-16958.

(29) Senger, M.; Mebs, S.; Duan, J.; Wittkamp, F.; Apfel, U.; Heberle, J.; Haumann, M.; Stripp, S. T. Stepwise Isotope Editing of [FeFe]-Hydrogenases Exposes Cofactor Dynamics. Proc. Natl. Acad. Sci. U. S. A. 2016, 113 (30), 8454-8459.

(30) Winkler, M.; Senger, M.; Duan, J.; Esselborn, J.; Wittkamp, F.; Hofmann, E.; Apfel, U.-P.; Stripp, S. T.; Happe, T. Accumulating the Hydride State in the Catalytic Cycle of [FeFe]Hydrogenases. Nat. commun. 2017, 8 (16115), 1-7.

(31) Senger, M.; Mebs, S.; Duan, J.; Shulenina, O.; Laun, K.; Kertess, L.; Wittkamp, F.; Apfel, 
U.-P.; Happe, T.; Winkler, M.; Haumann, M.; Stripp, S. T. Protonation/reduction Dynamics at the [4Fe-4S] Cluster of the Hydrogen-Forming Cofactor in [FeFe]Hydrogenases. Phys. Chem. Chem. Phys. 2018, 20, 3128-3140.

(32) Mebs, S.; Kositzki, R.; Duan, J.; Kertess, L.; Senger, M.; Wittkamp, F.; Apfel, U. P.; Happe, T.; Stripp, S. T.; Winkler, M.; Haumann, M. Hydrogen and Oxygen Trapping at the H-Cluster of [FeFe]-Hydrogenase Revealed by Site-Selective Spectroscopy and QM/MM Calculations. Biochim. Biophys. Acta - Bioenerg. 2018, 1859 (1), 28-41.

(33) Senger, M.; Laun, K.; Wittkamp, F.; Duan, J.; Haumann, M.; Happe, T.; Winkler, M.; Apfel, U. P.; Stripp, S. T. Proton-Coupled Reduction of the Catalytic [4Fe-4S] Cluster in [FeFe]-Hydrogenases. Angew. Chemie Int. Ed. 2017, 56 (52), 16503-16506.

(34) Mebs, S.; Senger, M.; Duan, J.; Wittkamp, F.; Apfel, U.-P.; Happe, T.; Winkler, M.; Stripp, S. T.; Haumann, M. Bridging Hydride at Reduced H-Cluster Species in [FeFe]Hydrogenases Revealed by Infrared Spectroscopy, Isotope Editing, and Quantum Chemistry. J. Am. Chem. Soc. 2017, 139, 12157-12160.

(35) Senger, M.; Stripp, S. T.; Soboh, B. Proteolytic Cleavage Orchestrates Cofactor Insertion and Protein Assembly in [NiFe]-Hydrogenase Biosynthesis. J. Biol. Chem. 2017, 292 (28), $11670-11681$.

(36) Moss, D.; Nabedryk, E.; Breton, J.; Mäntele, W. Redox-Linked Conformational Changes in Proteins Detected by a Combination of Infrared Spectroscopy and Protein Electrochemistry. Evaluation of the Technique with Cytochrome C. Eur. J. Biochem. 1990, $187(3), 565-572$.

(37) Adamska-Venkatesh, A.; Krawietz, D.; Siebel, J. F.; Weber, K.; Happe, T.; Reijerse, E.; 
Lubitz, W. New Redox States Observed in [FeFe] Hydrogenases Reveal Redox Coupling within the H-Cluster. J. Am. Chem. Soc. 2014, 136, 11339-11346.

(38) Fourmond, V.; Greco, C.; Sybirna, K.; Baffert, C.; Wang, P.-H.; Ezanno, P.; Montefiori, M.; Bruschi, M.; Meynial-Salles, I.; Soucaille, P.; Blumberger, J.; Bottin, H.; De Gioia, L.; Léger, C. The Oxidative Inactivation of FeFe Hydrogenase Reveals the Flexibility of the H-Cluster. Nat. Chem. 2014, 6 (4), 336-342.

(39) Miyake, T.; Bruschi, M.; Cosentino, U.; Baffert, C.; Fourmond, V.; Léger, C.; Moro, G.; De Gioia, L.; Greco, C. Does the Environment around the H-Cluster Allow Coordination of the Pendant Amine to the Catalytic Iron Center in [FeFe] Hydrogenases? Answers from Theory. J. Biol. Inorg. Chem. 2013, 18 (6), 693-700.

(40) Finkelmann, A. R.; Stiebritz, M. T.; Reiher, M. Inaccessibility of the $\mu$-Hydride Species in [FeFe] Hydrogenases. Chem. Sci. 2014, 5 (1), 215-221.

(41) Saouma, C. T.; Morris, W. D.; Darcy, J. W.; Mayer, J. M. Protonation and Proton-Coupled Electron Transfer at S-Ligated [4Fe-4S] Clusters. Chemistry (Easton). 2015, 21 (25), 9256-9260.

(42) Sommer, C.; Adamska-venkatesh, A.; Pawlak, K.; Birrell, J. A.; Rüdiger, O.; Reijerse, E. J.; Lubitz, W. Proton Coupled Electronic Rearrangement within the H-Cluster as an Essential Step in the Catalytic Cycle of [FeFe] Hydrogenases. J. Am. Chem. Soc. 2017, $139,1440-1443$.

(43) Nicolet, Y.; De Lacey, A. L.; Vernède, X.; Fernandez, V. M.; Hatchikian, E. C.; Fontecilla-Camps, J. C. Crystallographic and FTIR Spectroscopic Evidence of Changes in Fe Coordination upon Reduction of the Active Site of the Fe-Only Hydrogenase from 
Desulfovibrio Desulfuricans. J. Am. Chem. Soc. 2001, 123 (8), 1596-1601.

(44) Ogata, H.; Nishikawa, K.; Lubitz, W. Hydrogens Detected by Subatomic Resolution Protein Crystallography in a [NiFe] Hydrogenase. Nature 2015, 520 (7548), 571-574.

(45) Bruschi, M.; Greco, C.; Kaukonen, M.; Fantucci, P.; Ryde, U.; De Gioia, L. Influence of the $[2 \mathrm{Fe}] \mathrm{H}$ Subcluster Environment on the Properties of Key Intermediates in the Catalytic Cycle of [FeFe] Hydrogenases: Hints for the Rational Design of Synthetic Catalysts. Angew. Chemie Int. Ed. 2009, 48 (19), 3503-3506.

(46) Zampella, G.; Fantucci, P.; De Gioia, L. Unveiling How Stereoelectronic Factors Affect Kinetics and Thermodynamics of Protonation Regiochemistry in [FeFe] Hydrogenase Synthetic Models: A DFT Investigation. J. Am. Chem. Soc. 2009, 131 (31), 10909-10917.

(47) Filippi, G.; Arrigoni, F.; Bertini, L.; De Gioia, L.; Zampella, G. DFT Dissection of the Reduction Step in H 2 Catalytic Production by [FeFe]-Hydrogenase-Inspired Models: Can the Bridging Hydride Become More Reactive Than the Terminal Isomer? Inorg. Chem. 2015, 54 (19), 9529-9542.

(48) Leidel, N.; Hsieh, C.-H.; Chernev, P.; Sigfridsson, K. G. V; Darensbourg, M. Y.; Haumann, M. Bridging-Hydride Influence on the Electronic Structure of an [FeFe] Hydrogenase Active-Site Model Complex Revealed by XAES-DFT. Dalt. Trans. 2013, 42 (21), 7539 .

(49) Chernev, P.; Lambertz, C.; Brünje, A.; Leidel, N.; Sigfridsson, K. G. V.; Kositzki, R.; Chung-Hung Hsieh, S. Y.; Rafael Schiwon, M. D.; Limberg, C.; Happe, T.; Haumann, M. Hydride Binding to the Active Site of [FeFe]-Hydrogenase. Inorg. Chem. 2014, 53 (22), $12164-12177$. 
(50) Adamska-Venkatesh, A.; Silakov, A.; Lambertz, C.; Rüdiger, O.; Happe, T.; Reijerse, E.; Lubitz, W. Identification and Characterization of The "super-Reduced" state of the HCluster in [FeFe] Hydrogenase: A New Building Block for the Catalytic Cycle? Angew. Chemie Int. Ed. 2012, 51 (46), 11458-11462.

(51) Ratzloff, M. W.; Artz, J. H.; Mulder, D. W.; Collins, R. T.; Furtak, T. E.; King, P. W.; King, P. W. CO-Bridged H-Cluster Intermediates in the Catalytic Mechanism of [FeFe]Hydrogenase CaI. J. Am. Chem. Soc. 2018, 140 (24), 7623-7628.

(52) Chongdar, N.; Birrell, J. A.; Pawlak, K.; Sommer, C.; Reijerse, E. J.; Rüdiger, O.; Lubitz, W.; Ogata, H. Unique Spectroscopic Properties of the H-Cluster in a Putative Sensory [FeFe] Hydrogenase. J. Am. Chem. Soc. 2018, 140, 1057-1068.

(53) Happe, T.; Naber, J. D. Isolation, Characterization and N-Terminal Amino Acid Sequence of Hydrogenase from the Green Alga Chlamydomonas Reinhardtii. Eur. J. Biochem. 1993, $214(2), 475-481$.

(54) Mulder, D. W.; Ratzloff, M. W.; Bruschi, M.; Greco, C.; Koonce, E.; Peters, J. W.; King, P. W. Investigations on the Role of Proton-Coupled Electron Transfer in Hydrogen Activation by [FeFe]-Hydrogenase. J. Am. Chem. Soc. 2014, 136 (43), 15394-15402.

(55) Mulder, D. W.; Guo, Y.; Ratzloff, M. W.; King, P. W. Identification of a Catalytic IronHydride at the H-Cluster of [FeFe]-Hydrogenase. J. Am. Chem. Soc. 2016, 139, 83-86.

(56) Greco, C.; Bruschi, M.; Gioia, L. De; Ryde, U. A QM / MM Investigation of the Activation and Catalytic Mechanism of Fe-Only Hydrogenases. Inorg. Chem. 2007, 46 (15), 5911-5921.

(57) Reijerse, E. J.; Pham, C. C.; Pelmenschikov, V.; Gilbert-wilson, R.; Adamska-venkatesh, 
A.; Siebel, J. F.; Gee, L. B.; Yoda, Y.; Tamasaku, K.; Lubitz, W.; Rauchfuss, T. B.;

Cramer, S. P. Direct Observation of an Iron-Bound Terminal Hydride in [FeFe]-

Hydrogenase by Nuclear Resonance Vibrational Spectroscopy. J. Am. Chem. Soc. 2017, 139 (12), 4306-4309.

(58)

Pelmenschikov, V.; Birrell, J. A.; Pham, C. C.; Mishra, N.; Wang, H.; Sommer, C.;

Reijerse, E.; Richers, C. P.; Tamasaku, K.; Yoda, Y.; Rauchfuss, T. B.; Lubitz, W.;

Cramer, S. P. Reaction Coordinate Leading to $\mathrm{H}_{2}$ Production in [FeFe]-Hydrogenase

Identified by Nuclear Resonance Vibrational Spectroscopy and Density Functional

Theory. J. Am. Chem. Soc. 2017, 139 (46), 16894-16902.

(59) Schultz, B.-J.; Mohrmann, H.; Lorenz-fonfria, V. A.; Heberle, J. Protein Dynamics

Observed by Tunable Mid-IR Quantum Cascade Lasers across the Time Range from 10 Ns to 1 S. Spectrochim. Acta - Part A Mol. Biomol. Spectrosc. 2017, 188, 666 - 674.

(60) Mirmohades, M.; Adamska-venkatesh, A.; Sommer, C.; Reijerse, E.; Lomoth, R.; Lubitz, W.; Hammarström, L. Following [FeFe] Hydrogenase Active Site Intermediates by TimeResolved Mid-IR Spectroscopy. J. Phys. Chem. Lett. 2016, 7, 3290-3293.

(61) Greene, B. L.; Vansuch, G. E.; Chica, B. C.; Adams, M. W. W.; Dyer, R. B. Applications of Photogating and Time Resolved Spectroscopy to Mechanistic Studies of Hydrogenases. Acc. Chem. Res. 2017, 50 (11), 2718-2726.

(62) Greene, B. L.; Schut, G. J.; Adams, M. W. W.; Dyer, R. B. Pre-Steady-State Kinetics of Catalytic Intermediates of an [FeFe]-Hydrogenase. ACS Catal. 2017, 7, 2145-2150.

(63) Rauchfuss, T. B. Diiron Azadithiolates as Models for the [FeFe]-Hydrogenase Active Site and Paradigm for the Role of the Second Coordination Sphere. Acc. Chem. Res. 2015, 48 
(7), 2107-2116.

(64) Kosourov, S.; Seibert, M.; Ghirardi, M. L. Effects of Extracellular pH on the Metabolic Pathways in Sulfur-Deprived H2-Producting Chlamydomonas Reinhardtii under Different Growth Conditions. Plant Cell Physiol. 2003, 44 (2), 145-155.

(65) Thorsten Buhrke Antje Porthun, Bärbel Friedrich, O. L. The $\mathrm{H}_{2}$-Sensing Complex of Ralstonia Eutropha: Interaction between a Regulatory [NiFe] Hydrogenase and a Histidine Protein Kinase. Mol. Microbiol. 2004, 51 (6), 1677-1689.

(66) Taylor, B. L.; Zhulin, I. B. PAS Domains: Internal Sensors of Oxygen, Redox Potential, and Light. Microbiol. Mol. Biol. Rev. 1999, 63 (2), 479-506.

(67) Dau, H.; Haumann, M. The Manganese Complex of Photosystem II in Its Reaction CycleBasic Framework and Possible Realization at the Atomic Level. Coord. Chem. Rev. 2008, $252(3-4), 273-295$.

(68) Camara, J. M.; Rauchfuss, T. B. Combining Acid-base, Redox and Substrate Binding Functionalities to Give a Complete Model for the [FeFe]-Hydrogenase. Nat. Chem. 2012, $4(1), 26-30$. 